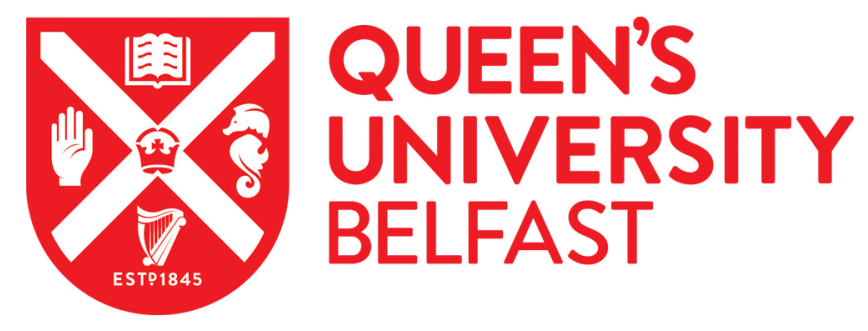

\title{
No association between routinely recorded infections in early life and subsequent risk of childhood-onset Type 1 diabetes: a matched case- control study using the UK General Practice Research Database
}

Cardwell, C., Carson, D., \& Patterson, C. (2008). No association between routinely recorded infections in early life and subsequent risk of childhood-onset Type 1 diabetes: a matched case-control study using the UK General Practice Research Database. Diabetic Medicine, 25(3), 261-267. https://doi.org/10.1111/j.1464-

5491.2007.02351.x

Published in:

Diabetic Medicine

Queen's University Belfast - Research Portal:

Link to publication record in Queen's University Belfast Research Portal

\section{General rights}

Copyright for the publications made accessible via the Queen's University Belfast Research Portal is retained by the author(s) and / or other copyright owners and it is a condition of accessing these publications that users recognise and abide by the legal requirements associated with these rights.

Take down policy

The Research Portal is Queen's institutional repository that provides access to Queen's research output. Every effort has been made to ensure that content in the Research Portal does not infringe any person's rights, or applicable UK laws. If you discover content in the

Research Portal that you believe breaches copyright or violates any law, please contact openaccess@qub.ac.uk. 


\title{
Original Article: Epidemiology
}

\section{No association between routinely recorded infections in early life and subsequent risk of childhood-onset Type 1 diabetes: a matched case-control study using the UK General Practice Research Database}

\author{
C. R. Cardwell, D. J. Carson and C. C. Patterson \\ School of Medicine and Dentistry, The Queen's University of Belfast, Belfast, UK \\ Accepted 11 October 2007
}

\begin{abstract}
Aims To determine whether children with infections in early life (recorded routinely in general practice) have a reduced risk of Type 1 diabetes, as would be expected from the hygiene hypothesis.

Methods Children with Type 1 diabetes and up to 20 matched (on year of birth, sex and region) control subjects were selected from a cohort of children born in the UK at General Practice Research Database practices. For each child, the frequency of general practitioner consultations for infections and prescriptions for antibiotics in the first year of life were determined. Odds ratios (ORs) and 95\% confidence intervals (95\% CIs) were calculated using conditional logistic regression.

Results The main analysis included 367 case and 4579 matched control subjects. There was no evidence of any reduction in the subsequent risk of Type 1 diabetes in children with at least one infection in the first year of life $(\mathrm{OR}=1.03,95 \% \mathrm{CI}$ $0.79,1.34)$ or in children prescribed antibiotics in the first year of life $(\mathrm{OR}=1.03,95 \% \mathrm{CI} 0.82,1.29)$. Further analyses also revealed little evidence of a difference in subsequent risk of Type 1 diabetes after different types of infection in the first year of life (including gastrointestinal, conjunctivitis, otitis media and upper and lower respiratory tract). Analyses of infections in the first 2 years of life reached similar conclusions.
\end{abstract}

Conclusions This study provides no evidence of an association between infections in early life and subsequent risk of childhood-onset Type 1 diabetes and therefore does not support the hygiene hypothesis.

Diabet. Med. 25, 261-267 (2008)

Keywords epidemiology, infection

Abbreviations CI, confidence interval; GP, general practitioner; GPRD, General Practice Research Database; OR, odds ratio; OXMIS, Oxford Medical Information Systems

\section{Introduction}

The hygiene hypothesis suggests that the developing immune system requires stimulation by the environment to achieve a mature and balanced repertoire of responses [1,2]. Consequently, reduced or delayed exposure to infection at an early age could increase the risk of an abnormal immune response potentially precipitating the onset of Type 1 diabetes. In support of this theory, various studies have demonstrated a

Correspondence to: Chris Cardwell, Department of Epidemiology and Public Health, The Queen's University of Belfast, Grosvenor Road, Belfast BT12 6BJ, UK. E-mail: c.cardwell@qub.ac.uk protective effect of proxy measures for exposure to infection, such as later birth order [3-5] and day-care attendance [6-8]. However, only two studies $[9,10]$ have investigated Type 1 diabetes and routinely recorded infections in the first year of life and both had relatively small numbers, 58 and 108 cases respectively. Other studies of Type 1 diabetes and infections in early life $[6,7,11-13]$ have ascertained infection from parental recall, which is an unreliable source of infection data [14].

The General Practice Research Database (GPRD) affords the opportunity to conduct the largest investigation to date of Type 1 diabetes and routinely recorded infections (and prescribed antibiotics) in early life to determine if children experiencing infections in early life had a reduced subsequent 
risk of Type 1 diabetes, as would be expected from the hygiene hypothesis.

\section{Patients and methods}

\section{The General Practice Research Database}

The GPRD was established in 1987 and is one of the world's largest databases of anonymized longitudinal medical records from primary care. It holds information on over 3 million patients, from over 400 practices, across the UK. Participating practices are audited to ensure that patient records include $95 \%$ of prescribing and relevant patient encounter events. Prescriptions are coded on the database with Prescription Pricing Authority codes. Medical conditions are coded with a modification of the Oxford Medical Information System (OXMIS) classification and Read codes [15]. The diagnostic and prescription data recorded in the GPRD have been validated by several studies $[16,17]$. Ethical approval for all observational research using GPRD data has been obtained from a Multicentre Research Ethics Committee (MREC).

\section{Cases and controls}

A cohort was established containing children born at 'up to standard' GPRD practices since the inception of the GPRD in 1987. Practices were declared 'up to standard' based upon audits of data quality conducted by the GPRD. Children without a recorded birth month, for whom the first year of life (the exposure period of interest) could not be determined, were excluded. Case and control subjects were identified from within the remainder of this cohort. Cases (with Type 1 diabetes) were identified in the cohort only if their records contained a prescription for insulin prior to their 15 th birthday. Ascertainment of cases was checked by investigating records of diagnoses. Control subjects were matched to individual cases from the cohort by gender, year of birth and GPRD health region (partitioning the UK into eleven regions). For each case, 20 control subjects were randomly selected from the available matches in the cohort. Data were extracted from the GPRD in August 2006.

The following additional exclusions were applied to the case and control subjects to maximize follow-up of the first year of life (the exposure period of interest). (i) Case and control subjects were excluded who were not registered on the GPRD within 3 months of birth, as registration rates after 3 months were low and stable, consistent with routine re-registration because of changing general practitioners (GPs). This 3-month cut-off has been used for the same reasons in a previous GPRD study of infections in early life and atopic disease [18]. (ii) Cases were excluded if they had a prescription for insulin or a diagnosis code for Type 1 diabetes prior to their first birthday. (iii) Case and control subjects were excluded if there was a record of them leaving the practice in the first year of life.

\section{Infections, antibiotics and vaccinations}

Comprehensive lists of OXMIS and Read codes were assembled for infection and symptoms usually associated with infection (which included diarrhoea, fever, pyrexia, sore throat, earache, snuffles, vomiting and diarrhoea, dysuria, otorrhoea and chesty cough). These lists were manually checked by a paediatrician (DC). Full lists of OXMIS and READ codes are available from authors on request. A case or control was considered to have an infection if they had a consultation in the first year of life at which an infection code was recorded. Over $90 \%$ of consultations during which an infection code was recorded in the first year of life involved direct contact with a GP (such as clinic visits and house calls) or other health professional (such as hospital discharge details and letters from outpatients etc.), but other consultations were also considered relevant (such as telephone calls). A count of the number of consultations for infection was extracted for the first year of life. Multiple consultations for an infection on the same day were only counted once to reduce repeatedly counting the same infection. For exploratory analyses, where possible, infection codes were categorized into the following groups: upper respiratory tract, lower respiratory tract, otitis media, conjunctivitis, gastrointestinal, urinary tract and non-invasive fungal disease.

A list of antibiotic codes was assembled from the GPRD medicine codes, which comprised Chapter 5 of the British National Formulary (BNF) [19], excluding section 5.4.1 (Antimalarials). A separate list of topical antibiotics was also assembled. The number of occurrences of these antibiotic codes in the first year of life was then extracted from GPRD prescription data.

The history of several common vaccinations and immunizations in the first year of life was extracted from GPRD immunization data.

\section{Statistical analysis}

Initially, the proportions of case and control subjects with recorded infections, prescribed antibiotics and immunizations were calculated. Conditional logistic regression was then used to calculate odds ratios (ORs), and $95 \%$ confidence intervals ( $95 \% \mathrm{CIs}$ ), to compare case and control subjects with respect to infections, vaccinations and antibiotics in the first year of life. To adjust for the propensity to consult a GP, a variable counting non-infection-related consultations in the first year of life was added to the conditional logistic regression model. A sensitivity analysis was conducted restricting case and control subjects to those registered on the GPRD within a month of birth, rather than 3 months, to investigate any impact of the delay between birth and registration. Planned subgroup analyses were also conducted investigating early (diagnosed prior to their fifth birthday) onset cases and later onset (diagnosed after their fifth birthday) cases separately. Finally, the main analysis was re-conducted investigating recorded infections and prescribed antibiotics in the first 2 years of life. This analysis excluded children who left their GP before their second birthday and cases which were diagnosed with Type 1 diabetes before their second birthday.

A power calculation was conducted prior to analysis based upon an unmatched analysis of 350 cases of Type 1 diabetes with ten control subjects per case, assuming $75 \%$ of control subjects had at least one recorded infection in the first year of life. This calculation suggested the study would have over $80 \%$ power to detect as significant at the $5 \%$ level a reduction in the 


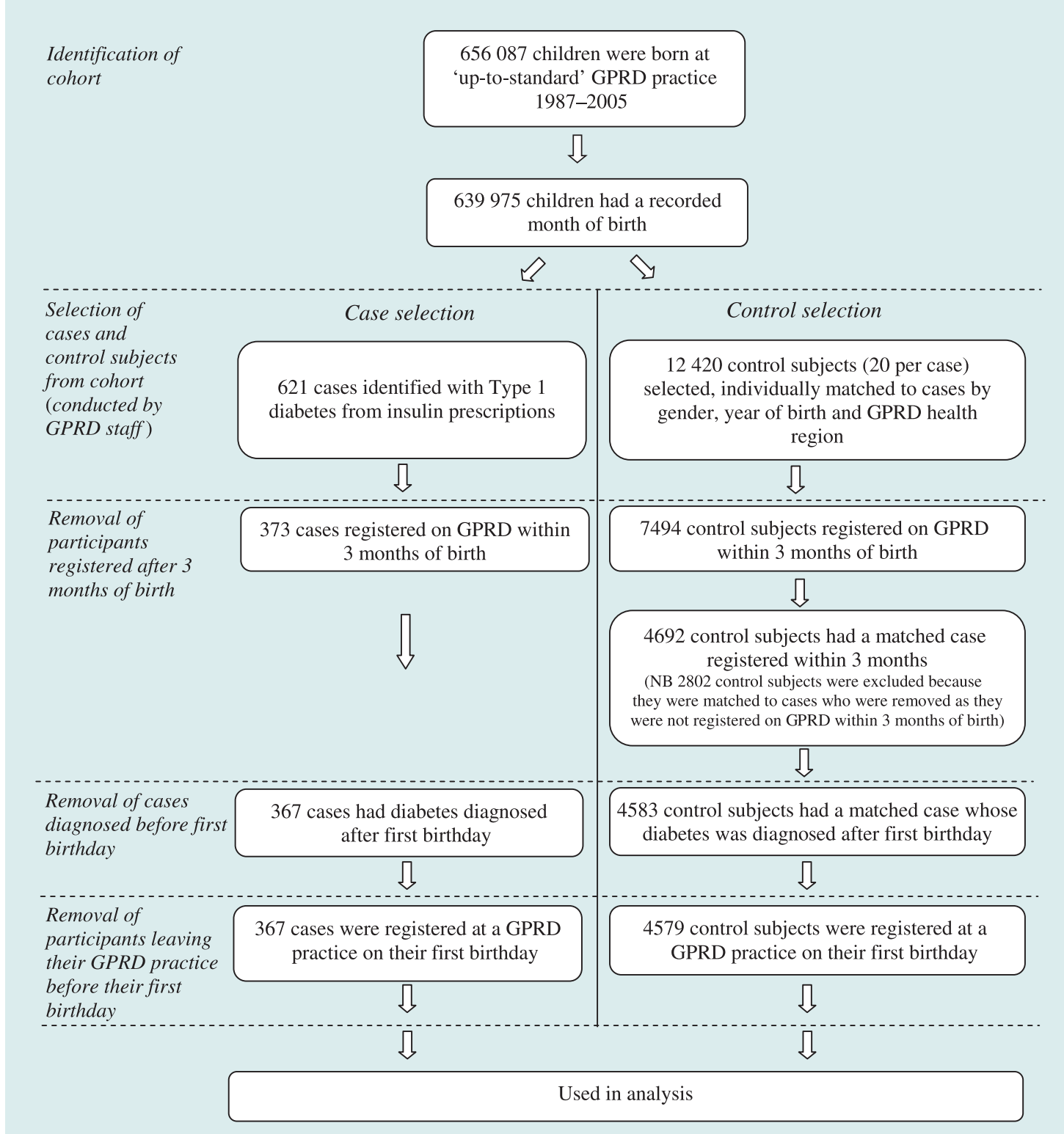

FIGURE 1 Flow chart showing selection of 367 cases and 4579 control subjects for analysis. GPRD, General Practice Research Database.

risk of Type 1 diabetes of $30 \%$ (an OR of 0.70 ) in children with at least one recorded infection in the first year of life.

All statistical analyses were performed using STATA release 8.0 (Stata Corporation, College Station, TX, USA).

\section{Results}

Figure 1 contains a flowchart describing how the dataset used in the analysis was obtained. The flow chart shows that 621 children were identified as cases because they had a recorded prescription for insulin. Of the 621 cases, 610 (98\%) had a diagnosis of diabetes, including 519 with Type 1 diabetes. There were 15 children with a recorded diagnosis of diabetes, including 10 with Type 1 diabetes, who were excluded as they did not have a record of insulin prescriptions.

The dataset used for analysis contained 367 cases and 4579 matched control subjects. The numbers of matched control subjects for each case ranged from 2 to 20 (mean $=12$, SD $=4)$. Table 1 contains patient characteristics of the cases and matched control subjects used in the analysis. The majority of cases of Type 1 diabetes were early onset cases (47\% were diagnosed prior to age 5 years and $40 \%$ were diagnosed between ages 5 and 9 years), reflecting the follow-up available in various age groups of the cohort of children born at GPRD practices since 1987. Specifically, all cases of childhood-onset Type 1 diabetes would be identified in children born earlier in 
Table 1 Characteristics of cases with Type 1 diabetes $(n=367)$ and matched control subjects $(n=4579)$

\begin{tabular}{|c|c|c|c|c|c|}
\hline \multirow[b]{2}{*}{ Characteristics } & \multicolumn{2}{|c|}{ Type 1 diabetes } & \multicolumn{2}{|c|}{ Control subjects } & \multirow[b]{2}{*}{$P$} \\
\hline & Mean (SD) & $n(\%)$ & Mean (SD) & $n(\%)$ & \\
\hline \multicolumn{6}{|l|}{ Sex } \\
\hline Male & & $167(46)$ & & $2077(45)$ & \\
\hline Female & & $200(54)$ & & $2502(55)$ & \\
\hline Age at data extraction (years) & $10.6(3.6)$ & & $10.0(3.7)$ & & \\
\hline \multicolumn{6}{|l|}{ Country } \\
\hline England & & $305(83)$ & & $3740(82)$ & \\
\hline Scotland & & $27(7)$ & & $340(7)$ & \\
\hline Northern Ireland & & $19(5)$ & & $283(6)$ & \\
\hline Wales & & $16(4)$ & & $216(5)$ & \\
\hline Age at diagnosis (years) & $5.9(3.4)$ & & & & \\
\hline $0-4$ & & $173(47)$ & & & \\
\hline $5-9$ & & $146(40)$ & & & \\
\hline $10-14$ & & $48(13)$ & & & \\
\hline \multicolumn{6}{|c|}{ GP consultations in the first year of life } \\
\hline At least one consultation* & & $366(100)$ & & $4546(99)$ & $0.25 \mathbb{S}$ \\
\hline Number of consultations* & $9(9) \ddagger$ & & $9(9) \ddagger$ & & \\
\hline $0-4$ & & $54(15)$ & & $690(15)$ & $0.16 \mathbb{S}$ \\
\hline $5-9$ & & $145(40)$ & & $1628(36)$ & \\
\hline $10-14$ & & $69(19)$ & & $1091(24)$ & \\
\hline$\geq 15$ & & $99(27)$ & & $1170(26)$ & \\
\hline At least one direct consultation $†$ & & $359(98)$ & $4463(97)$ & $0.53 \rrbracket$ & \\
\hline Number of direct consultations $†$ & $6(6) \ddagger$ & & $7(6) \ddagger$ & & \\
\hline $0-4$ & & $121(33)$ & & $1447(32)$ & $0.58 \mathbb{S}$ \\
\hline $5-9$ & & $147(40)$ & & $1834(40)$ & \\
\hline $10-14$ & & $56(15)$ & & $820(18)$ & \\
\hline$\geq 15$ & & $43(12)$ & & $478(10)$ & \\
\hline $\begin{array}{l}\text { "Includes GP surgery consultation } \\
\text { immunizations. } \\
\text { †Includes GP surgery consultation } \\
\ddagger \text { Median (interquartile range) pres } \\
\$ P \text {-value from conditional logistic } \\
\text { GP, general practitioner; sD, stand }\end{array}$ & $\begin{array}{l}\text { tations, hous } \\
\text { tations and h } \\
\text { le positively } \\
\text { ng variable as }\end{array}$ & $\begin{array}{l}\text { hone calls, n } \\
\text { s; excludes c } \\
\text { ical. }\end{array}$ & ions for imm & $\begin{array}{l}\text { excludes con } \\
\text { s. }\end{array}$ & s for \\
\hline
\end{tabular}

the cohort, while only earlier onset cases of Type 1 diabetes would be identified in children born later in the cohort.

The percentage of cases and control subjects with at least one consultation with their GP in the first year of life was similar $(99.7$ and $99.3 \%$ respectively, $P=0.25)$. There was no evidence of a difference in the number of consultations in the first year of life between the cases and control subjects (both medians were $9, P=0.16$ ). Similarly, there was no evidence of a difference between cases and control subjects with respect to the proportion and number of direct consultations (consisting only of GP surgery consultations, clinic visits and house calls).

\section{Infections}

A summary of the comparison of consultations for infections in the first year of life between cases and control subjects is contained in Table 2. There was no evidence of any difference in the percentage of cases and control subjects with at least one consultation for an infection in the first year of life (79 and $79 \%$, respectively). The risk of Type 1 diabetes in children with at least one recorded infection was similar when compared with children with none $(\mathrm{OR}=1.03, P=0.85)$. There was also no evidence of a difference in the number of recorded infections in the first year of life between the cases and control subjects and consequently no evidence of any reduction in the risk of Type 1 diabetes with frequency of infection $(P$ for trend $=0.46$ ). The analysis of infections and associated symptoms is also shown in this table and produced no evidence of any associations. Finally, Table 2 also shows no evidence of any association between Type 1 diabetes and consultations in the first year of life for any specific types of infection (including upper respiratory tract, lower respiratory tract, otitis media, conjunctivitis, gastrointestinal, urinary tract and fungal).

\section{Antibiotics}

A summary of the comparison of prescriptions for antibiotics in the first year of life between cases and control subjects is contained in Table 3. In the first year of life, the percentage of cases and control subjects prescribed antibiotics was almost 
Table 2 Consultations for infection in the first year of life by children with Type 1 diabetes $(n=367)$ and matched control subjects $(n=4579)$

\begin{tabular}{|c|c|c|c|c|}
\hline Consultations & $\begin{array}{l}\text { Type } 1 \text { diabetes } \\
n(\%)\end{array}$ & $\begin{array}{l}\text { Control subjects } \\
n(\%)\end{array}$ & OR $(95 \% \mathrm{CI})$ & $P$ \\
\hline At least one consultation for infection & $289(79)$ & $3596(79)$ & $1.03(0.79,1.34)$ & 0.85 \\
\hline \multicolumn{5}{|l|}{ Total consultations for infections } \\
\hline 0 & $78(21)$ & $983(21)$ & 1.00 (Ref. Cat.) & \multirow{3}{*}{$\begin{array}{c}0.30 \\
(0.46) *\end{array}$} \\
\hline $1-2$ & $144(39)$ & $1651(36)$ & $1.13(0.85,1.51)$ & \\
\hline$\geq 3$ & $145(40)$ & $1945(42)$ & $0.93(0.70,1.25)$ & \\
\hline At least one consultation for infection or symptoms associated with infection & $296(81)$ & $3771(82)$ & $0.90(0.68,1.19)$ & 0.46 \\
\hline \multicolumn{5}{|c|}{ Total consultations for infections or symptoms associated with infection } \\
\hline 0 & $71(19)$ & $808(18)$ & 1.00 (Ref. Cat.) & \multirow{3}{*}{$\begin{array}{c}0.49 \\
(0.25)^{*}\end{array}$} \\
\hline $1-2$ & $121(33)$ & $1465(32)$ & $0.96(0.71,1.31)$ & \\
\hline$\geq 3$ & $175(48)$ & $2306(50)$ & $0.86(0.64,1.15)$ & \\
\hline \multicolumn{5}{|l|}{ At least one consultation for } \\
\hline Upper respiratory tract infections & $188(51)$ & $2532(55)$ & $0.84(0.67,1.04)$ & 0.11 \\
\hline Lower respiratory tract infections & $29(8)$ & $443(10)$ & $0.81(0.55,1.20)$ & 0.28 \\
\hline Otitis media & $73(20)$ & 777 (17) & $1.18(0.90,1.55)$ & 0.22 \\
\hline Conjunctivitis & $118(32)$ & $1339(29)$ & $1.14(0.90,1.43)$ & 0.27 \\
\hline Gastrointestinal infections & $25(7)$ & $352(8)$ & $0.91(0.59,1.38)$ & 0.64 \\
\hline Urinary tract infections & $2(1)$ & $56(1)$ & $0.46(0.11,1.90)$ & 0.23 \\
\hline Fungal infections & $60(16)$ & $665(15)$ & $1.15(0.86,1.54)$ & 0.34 \\
\hline
\end{tabular}

*Test for trend across categories.

CI, confidence interval; OR, odds ratio; Ref. Cat., reference category.

Table 3 Antibiotic prescriptions and vaccinations in the first year of life to children with Type 1 diabetes $(n=367)$ and matched control subjects $(n=4579)$

\begin{tabular}{|c|c|c|c|c|}
\hline Exposure & $\begin{array}{l}\text { Type } 1 \text { diabetes } \\
n(\%)\end{array}$ & $\begin{array}{l}\text { Control subjects } \\
n(\%)\end{array}$ & OR $(95 \% \mathrm{CI})$ & $P$ \\
\hline \multicolumn{5}{|l|}{ Antibiotic prescribing } \\
\hline At least one prescription for an antibiotic* & $231(63)$ & $2835(62)$ & $1.03(0.82,1.29)$ & 0.82 \\
\hline \multicolumn{5}{|l|}{ Antibiotic prescribing frequency } \\
\hline 0 & $136(37)$ & $1744(38)$ & 1.00 (Ref. Cat.) & 0.95 \\
\hline $1-2$ & $151(41)$ & $1835(40)$ & $1.04(0.81,1.33)$ & $(0.93) \dagger$ \\
\hline$\geq 3$ & $80(22)$ & $1000(22)$ & $1.00(0.75,1.35)$ & \\
\hline $\begin{array}{l}\text { At least one prescription for a topical antibiotic } \\
\text { Vaccinations }\end{array}$ & $203(55)$ & $2477(54)$ & $1.05(0.85,1.30)$ & 0.65 \\
\hline \multicolumn{5}{|l|}{ At least one recorded dose of } \\
\hline Pertussis & $361(98)$ & $4479(98)$ & $1.33(0.57,3.07)$ & 0.49 \\
\hline Haemophilus influenzae type B & $306(83)$ & $3919(86)$ & $1.05(0.58,1.92)$ & 0.87 \\
\hline Meningitis C & $71(19)$ & $1081(24)$ & $0.82(0.34,1.97)$ & 0.66 \\
\hline Tuberculosis & $7(2)$ & $109(2)$ & $0.76(0.34,1.67)$ & 0.47 \\
\hline Diptheria, tetanus, polio & $367(100)$ & $4516(99)$ & - & - \\
\hline Measles, mumps and rubella & $15(4)$ & $122(3)$ & $1.53(0.88,2.68)$ & 0.15 \\
\hline
\end{tabular}

identical, (63 vs. $62 \%$ respectively, $P=0.82$ ). There was no evidence of any association between the risk of Type 1 diabetes and number of prescriptions for antibiotics $(P$ for trend $=0.93$ ). Similarly, there was no evidence of any difference between the proportion of prescriptions for topical antibiotics in the cases and control subjects $(P=0.65)$.

\section{Vaccinations}

Table 3 also contains a comparison of the proportion of cases and control subjects receiving at least one dose of several vaccines in the first year of life. There was no evidence of any association between receiving at least one dose of any of the 
vaccines in the first year of life and the subsequent risk of Type 1 diabetes.

\section{Sensitivity analyses}

The findings for infections and antibiotics were not altered after adjustment for non-infection related consultations to account for the propensity to consult a GP (data not shown). The results were also similar after restricting cases and control subjects to those registered within 1 month of birth (data not shown), indicating that the delay between birth and registration had little impact on the findings. There was no evidence of any difference in the associations in early and later onset cases (data not shown). Finally, a comparison of consultations for infections, and infections and associated symptoms in the first 2 years of life was conducted. There was no evidence $(P=0.07)$ of any reduction in the proportion of cases $(92 \%$; $296 / 322$ ) compared with control subjects (89\%; 3400/3829) with one or more infection in the first 2 years of life. Similarly, there was no evidence $(P=0.18)$ of any difference between the proportion of cases $(93 \% ; 300 / 322)$ and control subjects $(91 \% ; 3486 / 3829)$ with one or more infection or associated symptom in the first 2 years of life.

\section{Discussion}

This study does not provide any evidence of an association between routinely recorded infections, prescribed antibiotics or vaccinations in early life and subsequent risk of childhoodonset Type 1 diabetes in the UK.

The main strength of this study is that consultations for infections and prescribed antibiotics in early life were routinely recorded by the GP prior to disease onset, reducing any possibility of recall or selection biases. Also, the timing of infections was recoded in the GPRD database, allowing the investigation of infections occurring in early life, considered in the hygiene hypothesis to be the critical period for the developing immune system [2].

This study has a number of weaknesses. First, the GPRD database of primary care records is likely to underestimate the number of infections experienced by a child in the first year of life, as parents may not consult the GP for every infection, particularly less severe infections such as enterovirus infections. This is unlikely to impact upon our findings, as there does not seem to be any obvious reason for the degree of underreporting to differ between the cases and control subjects. Furthermore, the rate of infections in the first year of life in this study was similar to that observed in a recent UK study of childhood leukaemia [20] which ascertained infections directly from primary care records (both averaged three infections in the first year of life in the general population). Another weakness was the delay between the date of birth and the date of GPRD registration of cases and control subjects, which could have lead to the under-ascertainment of infections in the first few months of life. However, in the main analysis, this delay was identical between cases and control subjects and the findings were little altered when the analysis was restricted to children registered within 1 month of birth. Finally, data on other known risk factors for Type 1 diabetes, such as birth order [3$5,21]$ and deprivation [22-24], were not available, but it seems unlikely that confounding would conceal a real reduction in the risk of Type 1 diabetes with infections (and antibiotics) in the first year of life.

Our findings are in contrast to the only two previous studies $[9,10]$ which have investigated routinely recorded infections in early life as a risk factor for Type 1 diabetes. A UK study [9] based upon 58 cases observed a significant inverse association between infection and diabetes, and a Lithuanian study [10] based upon 108 cases observed a slight although non-significant inverse association between infection and diabetes. As our current study is much larger than these studies, the association between infection and diabetes was estimated more precisely. Other studies, which have investigated the association between Type 1 diabetes and infections in early life, have ascertained infection primarily from parental recall. Two studies demonstrated no evidence of an association between various infections in childhood and diabetes risk $[6,12]$ and another two studies demonstrated slight although non-significant inverse associations between infections in the first year of life and diabetes risk $[7,11]$. Additionally, two of these studies $[6,11]$ observed no association between antibiotic use and diabetes risk, in accordance with our findings. These studies are likely to be less reliable than our study, as infection data were ascertained by parental recall, which is open to disease-dependent recall bias and has been shown to be an unreliable measure of both the timing and occurrence of infections [14].

The hygiene hypothesis suggests that the developing immune system requires stimulation by exposure to infections and other immune challenges to acquire a mature and balanced repertoire of responses [1,2]. This theory suggests that reduced or delayed exposure to infections may increase the risk of an abnormal immune response potentially precipitating Type 1 diabetes. Our study found no evidence of a lower subsequent risk of Type 1 diabetes in children who experienced infections in early life and consequently does not support this theory. Interestingly, no clear evidence has been found for an association between diabetes and enterovirus infections [25], but this could reflect limitations in the design of studies investigating such associations. Currently, a number of prospective studies are in progress, which may help clarify this issue [26,27].

The finding of no association between Type 1 diabetes and vaccinations is consistent with previous studies of Type 1 diabetes and vaccinations [6,28-31]. However, for many of the vaccinations, there was little power to detect associations with Type 1 diabetes, as only a small proportion of children were unvaccinated.

In conclusion, this study does not provide any evidence of an association between routinely recorded infections in early life and subsequent risk of childhood-onset Type 1 diabetes in the UK and therefore does not support the hygiene hypothesis. 


\section{Acknowledgements}

This study is based in part on data from the Full Feature General Practice Research Database obtained under licence from the UK Medicines and Healthcare Products Regulatory Agency. However, the interpretation and conclusions contained in this study are those of the authors alone. Access to the GPRD database was funded through the Medical Research Council's licence agreement with MHRA. We would like to thank Tarita Murray-Thomas for her assistance providing the GPRD data.

\section{Competing interests}

None to declare.

\section{References}

$1 \mathrm{Kolb} \mathrm{H}$, Elliott RB. Increasing incidence of IDDM-a consequence of improved hygiene? Diabetologia 1994; 37: 729.

2 Gale EA. A missing link in the hygiene hypothesis? Diabetologia 2002; 45: 588-594.

3 Patterson CC, Carson DJ, Hadden DR, Waugh NR, Cole SK. A casecontrol investigation of perinatal risk factors for childhood IDDM in Northern Ireland and Scotland. Diabetes Care 1994; 17: 376381.

4 Cardwell CR, Carson DJ, Patterson CC. Parental age at delivery, birth order, birthweight and gestational age are associated with the risk of childhood Type 1 diabetes: a UK regional retrospective cohort study. Diabet Med 2005; 22: 200-206.

5 Stene LC, Magnus P, Lie RT, Sovik O, Joner G. Maternal and paternal age at delivery, birth order, and risk of childhood-onset Type 1 diabetes: population based cohort study. Br Med J 2001; 323: 369.

6 The EURODIAB Substudy 2 Study Group. Infections and vaccinations as risk factors for childhood Type I (insulin-dependent) diabetes mellitus: a multicentre case-control investigation. Diabetologia 2000; 43: 47-53.

7 McKinney PA, Okasha M, Parslow RC, Law GR, Gurney KA, Williams R et al. Early social mixing and childhood Type 1 diabetes mellitus: a case-control study in Yorkshire, UK. Diabet Med 2000; 17: 236-242.

8 Kaila B, Taback SP. The effect of day-care exposure on the risk of developing Type 1 diabetes: a meta-analysis of case-control studies. Diabetes Care 2001; 24: 1353-1358.

9 Gibbon C, Smith T, Egger P, Betts P, Phillips D. Early infection and subsequent insulin-dependent diabetes. Arch Dis Child 1997; 77: 384-385.

10 Pundziute-Lycka A, Urbonaite B, Dahlquist G. Infections and risk of Type I (insulin-dependent) diabetes mellitus in Lithuanian children. Diabetologia 2000; 43: 1229-1234.

11 Blom L, Nystrom L, Dahlquist G. The Swedish childhood diabetes study-vaccinations and infections as risk determinants for diabetes in childhood. Diabetologia 1991; 34: 176-181.

12 Soltesz G, Jeges S, Dahlquist G. Non-genetic risk determinants for Type I (insulin-dependent) diabetes-mellitus in childhood. Acta Paediatr 1994; 83: 730-735.

13 Sipetic S, Vlajinac H, Kocev N, Radmanovic S. The Belgrade
Childhood Diabetes Study: association of infections and vaccinations on diabetes in childhood. Ann Epidemiol 2003; 13: 645-651.

14 McKinney PA, Alexander FE, Nicholson C, Cartwright RA, Carrette $\mathrm{J}$. Mothers' reports of childhood vaccinations and infections and their concordance with general practitioner records. J Public Health Med 1991; 13: 13-22.

15 Kinn S, Lee N, Millman A. ABC of medical computing. Using computers in clinical audit. Br Med J 1995; 311: 739-742.

16 Walley T, Mantgani A. The UK General Practice Research Database. Lancet 1997; 350: 1097-1099.

17 Hansell A, Hollowell J, Nichols T, McNiece R, Strachan D. Use of the General Practice Research Database (GPRD) for respiratory epidemiology: a comparison with the 4th Morbidity Survey in General Practice (MSGP4). Thorax 1999; 54: 413-419.

18 McKeever TM, Lewis SA, Smith C, Collins J, Heatlie H, Frischer M et al. Early exposure to infections and antibiotics and the incidence of allergic disease: a birth cohort study with the West Midlands General Practice Research Database. J Allergy Clin Immunol 2002; 109: 4350.

19 BMA and the RPSociety of Great Britain. British National Formulary. London: BMJ Publishing Group Ltd and Royal Pharmaceutical Society Publishing, 2006.

20 Roman E, Simpson J, Ansell P, Kinsey S, Mitchell CD, McKinney PA et al. Childhood acute lymphoblastic leukemia and infections in the first year of life: a report from the UK Childhood Cancer Study. Am J Epidemiol 2007; 165: 496-504.

21 Dahlquist G, Patterson C, Soltesz G. Perinatal risk factors for childhood Type 1 diabetes in Europe. The EURODIAB Substudy 2 Study Group. Diabetes Care 1999; 22: 1698-1702.

22 Patterson CC, Waugh NR. Urban/rural and deprivational differences in incidence and clustering of childhood diabetes in Scotland. Int J Epidemiol 1992; 21: 108-117.

23 Staines A, Bodansky HJ, McKinney PA, Alexander FE, McNally RJ, Law GR et al. Small area variation in the incidence of childhood insulin-dependent diabetes mellitus in Yorkshire, UK: links with overcrowding and population density. Int J Epidemiol 1997; 26: 1307-1313

24 Cardwell CR, Carson DJ, Patterson CC. Higher incidence of childhoodonset Type 1 diabetes mellitus in remote areas: a UK regional smallarea analysis. Diabetologia 2006; 49: 2074-2077.

25 Green J, Casabonne D, Newton R. Coxsackie B virus serology and Type 1 diabetes mellitus: a systematic review of published case-control studies. Diabet Med 2004; 21: 507-514.

26 Kupila A, Muona P, Simell T, Arvilommi P, Savolainen H, Hamalainen AM et al. Feasibility of genetic and immunological prediction of Type I diabetes in a population-based birth cohort. Diabetologia 2001; 44: 290-297.

27 The Environmental Determinants of Diabetes in the Young (TEDDY) study. Study design. Pediatr Diabetes 2007; 8: 286-298.

28 DeStefano F, Mullooly JP, Okoro CA, Chen RT, Marcy SM, Ward JI et al. Childhood vaccinations, vaccination timing, and risk of Type 1 diabetes mellitus. Pediatrics 2001; 108: E112.

29 Hviid A, Stellfeld M, Wohlfahrt J, Melbye M. Childhood vaccination and Type 1 diabetes. N Engl J Med 2004; 350: 1398-1404.

30 Karvonen M, Cepaitis Z, Tuomilehto J. Association between Type 1 diabetes and Haemophilus influenzae type $b$ vaccination: birth cohort study. Br Med J 1999; 318: 1169-1172.

31 Parent ME, Siemiatycki J, Menzies R, Fritschi L, Colle E. Bacille Calmette-Guerin vaccination and incidence of IDDM in Montreal, Canada. Diabetes Care 1997; 20: 767-772. 